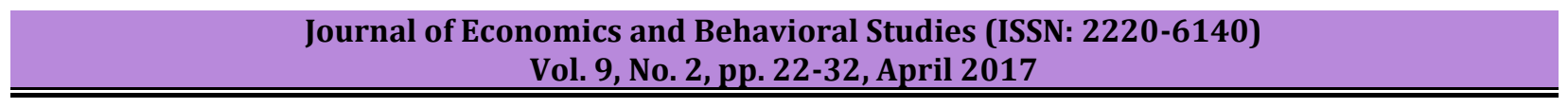

\title{
The Effects of Stress on Employee Productivity: A Perspective of Zimbabwe's Socio-Economic Dynamics of 2016
}

\author{
Wilford Mawanza \\ Lupane State University, Bulawayo, Zimbabwe \\ wmawanza@lsu.ac.zw
}

\begin{abstract}
This study was motivated by Zimbabwe's deteriorating economic experience, which has resulted in high unemployment rates, low productivity, high cost of doing business, increased labour disputes, and stress manifestation amongst the working population. The results of the study showed that change factors, demands or pressure factors, lack of support and participation at work by supervisors and other staff members, and work role were to a greater extent the most stressful factors. The perennial economic crisis in the country, high degree of uncertainty due to restructurings and redundancies, and work changes without consultations, had a positive impact on employee's productivity. The regression results concluded that poor work relationships, lack of support at work, and poor planning had negatively affected productivity.
\end{abstract}

Keywords: Work-related Stress, Productivity, Employee, Zimbabwe

\section{Introduction}

The study seeks to analyse the effects of stress on employee productivity in Zimbabwe and strategies an organisation may take to strike a balance of the two. Stress at work affects workers and their communities in the negative way, with some resultant clear financial impact on businesses, the economy and beyond. Stress manifest itself in various ways, among others include absence from work due to sickness, the hidden cost of a sick employee, present at work but not fully productive, and unemployment. Despite the fact that stress is a condition, not a disease, it sends signals for some looming problems. If the human body is subjected under unrestrained stress levels, this can result in malfunctioning of the body system and organs within the body, through acute and chronic changes. Dean (2002) postulated that illnesses related to stress are the leading cause for low productivity levels in organisations. The changing world of work, coupled together with the recent global economic crisis and recession are making increased demands on workers at local, national, regional and global levels. The concept of Globalisation and other dynamics like technological innovations, virtual office and network concepts, disintegration of the labour market, downsizing and outsourcing, greater need for flexibility in terms of both function and skills, increasing use of temporary and/or casual contracts, increased job insecurity, higher workload and pressure of performance, as well as poor work-life balance, are factors that contribute to work-related stress and add to the burden of stress around the world (http://www.theindependent.co.zw/ 2015). In practice, improving the quality of work life remains a big bone to chew. Lowe (2006) noted that most managers appreciate the relationship between the quality of work life and organizational performance though they face barriers to progress. So it is necessary to update the case for taking action to improve the quality of jobs and work environments.

According to Michac (1997) stress is induced by the following factors: poor time management, unclear job descriptions, feelings of inadequacy and insecurity, inability to get things done, lack of communication, bad personal relationships, quality and complexity of tasks. Industrial Psychology Consultants (IPC, 2014) conducted a survey and came up with the following statistics on stress and depression: that $27.3 \%$ of the working population was experiencing depression symptoms, namely feeling that things are meaningless, and they can't see a way of escaping from their situation, life is not worthwhile, they would be better if they were dead, they can't enjoy anything anymore, wishing they were dead. That $18.3 \%$ experiences anxiety symptoms and these include vague feelings of fear, trembling when with others, panic attacks, feeling frightened and fear of going out of the house alone. 33.4\% of the working population in Zimbabwe experience somatisation symptoms and these include headache, painful muscles, back pain, bloated feeling in the abdomen, neck pain, blurred vision, dizziness or feeling light-headed, nausea or an upset stomach, pressure or a tight feeling in the chest, pain in the chest, tingling in the fingers, excessive sweating, palpitations and fainting. The manufacturing sector was reported to have the highest prevalence of depression symptoms $(27.4 \%)$ followed by the financial sector (26.2\%) with IT and telecommunications (17.8\%) in third position (IPC, 2014). It is 
against this background that the research formulated the problem statement and research objectives, to examine the effects of such statistics on employee productivity.

Statement of Research Problem: In spite of the fact that work-related stress is a cause for concern with an increasing importance and that a number of studies on work-related stress have been produced with statistics, there is still a lack of adequate information in the developing world on a national or regional level to assess the magnitude of the problem and how that can influence the commensurate public policy. According to IPC (2014), distress and mental illness in the workplace is significantly higher (30\%) in Zimbabwe with the global average being around $15-25 \%$. The following statistics were given for stress level in different parts of the world

Table 1: Stress Statistics

\begin{tabular}{lll}
\hline $\begin{array}{l}\text { Area and source } \\
\text { (Maxon, 1999) }\end{array}$ & Statistics & Stress component \\
$\begin{array}{l}\text { USA } \\
\text { (Maxon, 1999) }\end{array}$ & $\begin{array}{l}\text { Describe work as stressful. } \\
\text { 26.2\% of adults over 18 years }\end{array}$ & $\begin{array}{l}\text { Suffer mental disorder } \\
\text { (NK }\end{array}$ \\
$\begin{array}{l}\text { Nearly 50\% of teachers have } \\
\text { considered quitting jobs }\end{array}$ & $\begin{array}{l}\text { Increased stress and cuts in pay and } \\
\text { pensions have led to high levels of } \\
\text { dissatisfaction in profession }\end{array}$ \\
$\begin{array}{l}\text { Zimb, 2014) } \\
\text { (IPC, 2014) }\end{array}$ & $30 \%$ of employees & $\begin{array}{l}\text { Experience depression symptoms } \\
\text { Global average } \\
\text { (IPC, 2014) }\end{array}$ \\
\hline
\end{tabular}

Given that Zimbabwe already suffers from a high rate of unemployment, productivity and high cost of doing business, more labour disputes and job cuts, a deteriorating economy, stress can manifest itself in several forms to the working population. Hence the need to study the effects of stress on employee's productivity, and policies that employers and the government can device to address issues of stress a workplace.

Socio-economic dynamics: For the purpose of this paper, socio-economic dynamics would refer to the effects, changes and interaction in of social and economic factors on employee stress. The economic downturns have been linked so much to a lot of restructurings in the labour market, some of which include recruitment freezes, unpaid leaves and layoffs. Consequently these economic and social factors interact to pose more stress on an average employee in Zimbabwe.

Main Objective and significance of the study: The objective of the study is to evaluate stress and its effect on employees' productivity and managerial responsibility in companies in Zimbabwe. This was motivated by the state of the socio-economic and political affair of the country which seemed to be on a recessionary trend and hence bring in with it a lot of problems and stress to employees and employers. The contributions of this research are threefold. For managers, the model to be developed in the study is expected to give a practical tool for developing a holistic understanding of the underlying causal and latent causes of stress and the need to ensure the effective management of stress for their employees. For policymakers, it will also provide suggestions on how to reduce the effects of stress on output. Finally, it brings a methodological innovation to the study of organizational behaviour which may be of interest for academicians and practitioners. Knowing that one has made a contribution to a specific area is tremendously fulfilling. It also brings personal gains in the form of expertise in organisational behaviour as a subject and this is the start of a lifetime's special interest. The study was carried out through a survey on employees from various companies in Bulawayo, Zimbabwe. 


\section{Literature Review}

The Wheel of Life of an employee is one important concept that can easily be put off balance by the quality of work and work related stress. The imbalance between work-life and work related stress had been a subject of study by many academics, practitioners and analysts and has received considerable attention across time, across geographical delineations and across social classes. This kind of an imbalance has an impact on the employees' well-being as well as to organizational performance. In order to come up with effective remedies, decision-makers need to understand the wheel of life for individual and solid evidence on the scope and nature of the problems they face. Equally helpful is a clear understanding of what employers and employees view as potential solutions (Lowe, 2006). According to Maxon (1999), the economic consequences of the physical effects of the stress epidemic are startling. They noted that US employers on average incur costs amounting to an estimated $\$ 200$ billion per year in absenteeism, lower productivity, staff turnover, workers' compensation, medical insurance and other stress-related expenses. The following is a review of theoretical and empirical literature on the subjects of study.

Concept of Stress: Robbins (2004) defined stress as a dynamic condition in which an individual is confronted with opportunity, constraint or demand related to what he desires and for which the outcome is perceived to be both uncertain and important. Imtiaz and Ahmad (2009) described Stress as a mental sprain that is associated with the internal or external spur that renounces a person to respond towards its environment in a normal manner. According to Treven (2005), stress is a universal experience in the life of every organisation and every executive, manager, and individual employee. It is a naturally occurring experience which may have beneficial or destructive consequences. The destructive consequences of a stressful experience are not inevitable. They only result from ineffective management of stress and stressful events. Stress was also described by Aldwin (1994) as the interaction of the employee and the work environment and the experience that is gained thereof. This interaction may lead to psychological and physiological tension. The ordinary disintegration of the body and as the non-specific response of the body to any demand placed on it is the manifestation of stress (Selye, 1964). They recognised the meaning of positive stress, which not only does not cause degeneration and malfunctions, but can also act as a productive factor and as a factor of development and creation.

Naqvi et al. (2013) noted that stress is a condition of physical and psychological mental disorder which occurs in a situation of pressure, when resources are unable to fulfil the demand of an individual. The major drivers of stress at work comes in the form of social relationships, work relationships with mates and supervisors, style of management, work overload, and other external economic factors. Miller \& Phipps (2011) carried a survey to measure the cost on absence due to stress both in the private and public sector and their results showed that stress resulted in a loss of 800 pounds in the public sector and 446 pounds per employee in the private sector.

Concept of Productivity: Meneze (2006) explained the concept of productivity as the employee's ability to produce work or goods and services according to the expected standards set by the employers, or beyond the expected standards. According to Bojke et al. (2012) one can calculate productivity by comparing total output to the total input used to produce this output. According to a Singapore guide to productivity measurement (2011), these productivity measures quantify and facilitate an objective assessment of employees' performance. They provide information on performance gaps and help to identify the training needs of employees. The guide defined Labour productivity, as "value added per worker, is the most common measure of productivity. It reflects the effectiveness and efficiency of labour in the production and sale of the output." The following table shows the various measures of productivity as published in the Singapore spring guide. 
Table 2: Measures of Productivity

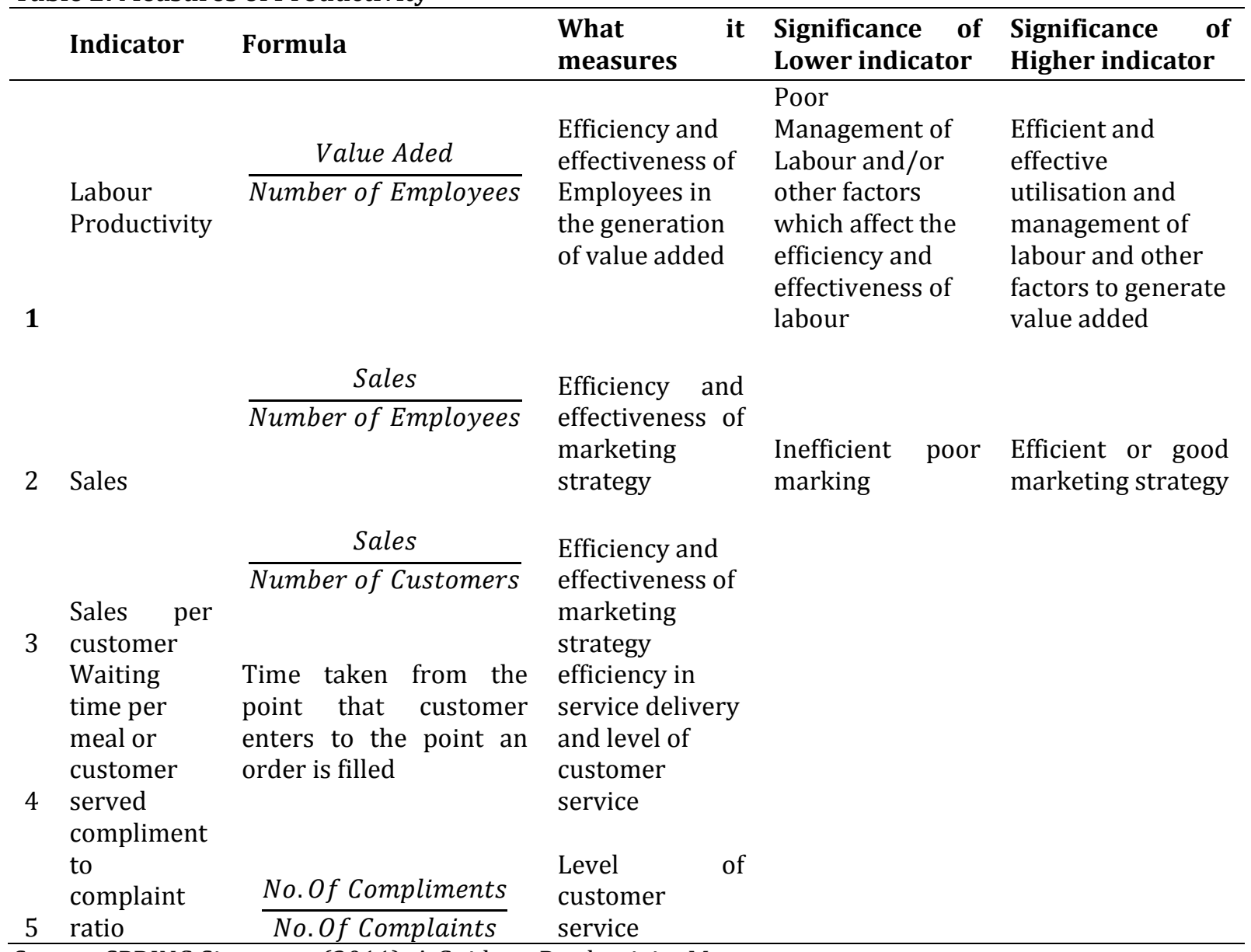

Source: SPRING Singapore (2011). A Guide to Productivity Measurement

The Organisation for Economic Co-operation and Development (OECD) (2001) identified the different types of productivity measures. The decision as to which one to be used in particular case depends on the purpose of productivity measurement and, in many instances, on the availability of data. Broadly, productivity measures can be classified as single factor productivity measures (relating a measure of output to a single measure of input) or multifactor productivity measures (relating a measure of output to a bundle of inputs). Another distinction, of particular relevance at the industry or firm level is between productivity measures that relate some measure of gross output to one or several inputs and those which use a value-added concept to capture movements of output (OECD, 2001).

Empirical Literature on stress and productivity: Imtiaz \& Ahmad (2009) carried out research on the impact of stress on employee productivity, performance and turnover in Twin Cities of Pakistan Rawalpindi/Islamabad, and identified the factors affecting stress as personal issues, lack of administrator support, lack of acceptance for work done, low span over work environment, unpredictability in work environment \&inadequate monetary reward. Their analysis showed immense support for negative relationship between stress and job performance. The results showed that with every unit; increase in personal dilemmas, decrease in financial reward, decrease in influence over work environment, decrease in supervisor support there would be $0.513,0.079,0.266,0.117$ decreases in job performance respectively. It was noted that levels of stress would increase if no managerial concern for solution is given to the employee and this would result in poor performance by the employee performance; staking organizational reputation and loss of skilled employees. Halkos and Bousinakis (2010) did a study to investigate the effects of stress and job satisfaction on the functioning of a company and their results showed that as expected, increased stress leads to reduced productivity and increased satisfaction leads to increased productivity. The overlap of work 
issues with employees' personal life negatively affects productivity. Motivated and satisfied workers produce quality work and resultantly affect productivity positively.

Bewell et al. (2014) examined work induced stress and its relationship to organizational effectiveness and productivity and concluded that the concept of work-induced stress, and workers effectiveness and productivity are relatively inseparable; and challenged the various organizations in Nigeria to employ the services of Organizational and Clinical Psychologists to help in providing stress coping skills, coaching and counselling to employees as it will help to boost efficiency and high productivity in various organization in Nigeria. Manzoor et al. (2012) carried out a research investigating the impact of work stress on job performance through a case study on Textile Sector of Faisalabad and their results showed that the stress levels among employees in textile sector of Faisalabad is high in certain areas like work overload and long work hours, affect on family life, pressure at work, job insecurity, and physical agents, however, this kind of stress is not affecting the performance of the employees. They concluded that the there is no relationship between job stress and employee performance.

The conceptual Framework: Given the vast literature and previous research on stress and employee productivity, a generalised model or conceptual framework can be developed consistent with previous theory that estimates the affects of level of stress on employee productivity. Two main constructs are included in the proposed research model below encompassing stress and employee productivity. The framework is generated for the various definitions and explanation derived from the above literature. The diagram below is a schematic presentation of the conceptual framework.

\section{Figure 1: The conceptual Framework}

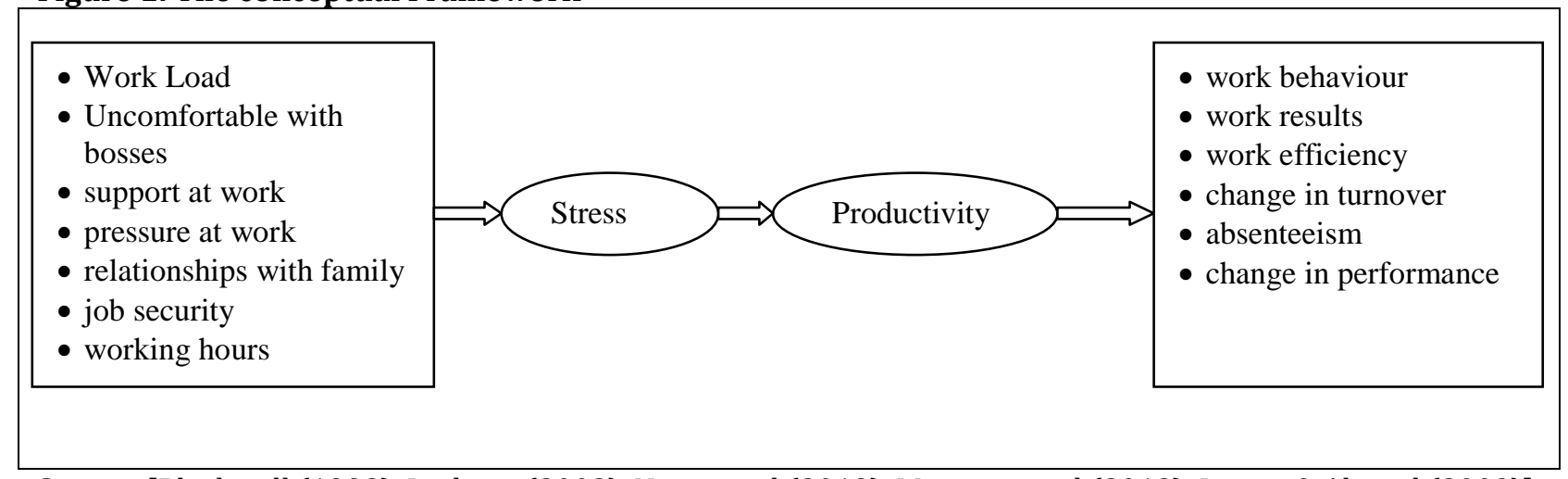

Source: [Blackwell (1998), Luthans (2002), Naqvi et al (2013), Manzoor et al (2012), Imtiaz \& Ahmad (2009)]

The conceptual framework was built up from the various results of previous research and empirical literature discussed above, on the variables affecting the vice under study. Blackwell (1998) stated that stress shows itself in a number of ways. For instance an individual who is experiencing a high level of stress may develop high blood pressure, ulcers and others. These can be grouped under three general categories; Physiological, Psychological and Behavioural symptoms. According to Luthans (2002) besides the potential stressors that occurred outside the organization, there were also those that were associated with the organization. Despite the fact that an organization is made up of groups of individuals, there are also more external factors that are not organizational specific that contains potential stressors. Most of the studies done on this topic showed that stress may be largely responsible for organizational outcomes such as decline in performance, dissatisfaction, lack of motivation and commitment, and an increase in absenteeism and turnover.

\section{Methodology}

The research design for this study was a descriptive survey research aimed at assessing stress and its effects on employees' productivity. Through the use of the descriptive survey the researcher seeks to probe deeply and analyse the factors that explain or influence the variable understudy. Its main advantage is that it produces a reasonable amount of responses from a wide range of respondents whilst providing a more 
accurate picture of events at a point in time. A descriptive study identifies and defines the problem, selects tools for collecting data, describes, analyzes and interprets the data (Creswell, 2003). This definition goes along with the objectives of this study as it has the potential to provide with a lot of information obtained from quite a large sample of individuals. Leedy and Ormrod (2001) noted that survey is an economic way of collecting a certain amount of data from a sizable population. The research methodology stretched from both primary data sources through to the secondary sources of data so as to reach out to as many opinions as possible in as far as the issue of stress and employee productivity was concerned.

Data collection methods: This involves how data was gathered from various sources both secondary and primary. The survey instrument involved questionnaires with both closed-ended and open-ended questions. Two main factors were considered in designing the questionnaire so as guarantee accuracy. These were

- Academic literature, research articles and publications.

- Pre-testing to ensure that the respondent understand the questionnaire in right perspective.

These questions were used to collect information relating to stress and productivity faced by employee and how they were able to control the effects. The intended respondents were any employee from any company regardless of the sector or industry. The aim of the questionnaire was to establish two main things. Firstly, to determine the employee stress factors. Secondly, to assess the effects of stress on identified productivity measure.

To determine if the questionnaire would gather the appropriate data, the questionnaire was pre-tested. Email distribution was used in some cases when the researcher used the Internet and social media platforms to send and receive the questionnaires. The method was cost effective in terms of time and money. Email also best suit the research in terms of time management and travel costs minimization. Email was also advantageous since the researcher and the respondents were using the same domain. Physical Distribution was used in sending the questionnaires in the researcher's metropolitan. Questionnaires were dropped at respondents' workplaces and a date convenient to both the researcher and the respondent was agreed for collection of the questionnaire.

Questionnaire design: The population of this study was centred more on employees working in various companies in Zimbabwe regardless of the sector. Given the size of the target population, it was difficult to conduct a census due to both financial and non-financial constraints such as time. It is with this in mind that sampling was inevitable in such a situation. The survey was appropriate through convenience sampling as it was a cost-effective and efficient means of gathering data given that the population of the study was very large and dispersed across a large geographic area.

\section{Data Analysis and Discussion of Results}

Out of the 200 questionnaires sent out, 189 were received representing 95 percent response rate. The data obtained from respondents were entered into an SPSS database application and analysed through descriptive statistics. This study investigated the effects of stress related factors on employee productivity and how companies deal with vice. The researcher started by conducting exploratory factor analysis using the statistical package, SPSS version 21in order to ascertain the validity of the instruments and other analysis of the quantitative data. The analysis started by the background information of the respondents, to check how gender, and age affected stress levels of an employee and the data was presented in table 3 below.

From the table a total of 175 respondents (92\%) concurred that they sometimes get stressed at work. Out of that figure, 67 were male respondents and 108 were female respondents. The statistics also showed that majority of the work force are in the age range of 30-39 years and 84 respondents indicated that they sometimes get stressed. This is indeed evidence that stress is common in Zimbabwe's work force though it varies in nature and factors causing it. A further investigation revealed that stress exist in all classes of the workforce no matter how longer they have served as an employee though it can be seen that stress increases with years of service. This is in line with Aftab and Javeed (2012) result, who also found out that that stress was significantly equal in all individuals having different professional experiences. Having analysed the 
background information and stress related experiences; the data was also tested to fulfil the requirements of the main objective of the study that is assessing the effects of stress on employee productivity.

Table 3: AGE * Stressed * GENDER Cross tabulation

\begin{tabular}{|c|c|c|c|c|c|}
\hline \multirow[b]{2}{*}{ GENDER } & & & \multicolumn{3}{|c|}{$\begin{array}{l}\text { Do you sometimes get stressed out } \\
\text { at work? }\end{array}$} \\
\hline & & & Yes & No & Total \\
\hline \multirow[t]{5}{*}{ Male } & AGE & 20-29 Years & 25 & 5 & 30 \\
\hline & & 30-39 Years & 25 & 0 & 25 \\
\hline & & 40-49Years & 15 & 1 & 16 \\
\hline & & 50 Years and Above & 2 & 0 & 2 \\
\hline & Total & & 67 & 6 & 73 \\
\hline \multirow[t]{5}{*}{ Female } & AGE & 20-29 Years & 34 & 2 & 36 \\
\hline & & 30-39 Years & 59 & 2 & 61 \\
\hline & & 40-49Years & 13 & 1 & 14 \\
\hline & & 50 Years and Above & 2 & 0 & 2 \\
\hline & Total & & 108 & 5 & 113 \\
\hline
\end{tabular}

The data collected was coded into the system using the Likert scale showing the severity of stress variables among each respondent. A four point Likert scale was used to measure the items where 1 represented "not stressful" and 4 "Very stressful". The objective was to measure the extent to which respondents were stressed by a certain variable. Productivity was treated as the dependent variable of the study and as was shown in the conceptual framework, it was broken down into further six items as on which a three point Likert scale was applied where 1 represented no change in that productivity measure, 2 representing a decrease in productivity and 3 being an increase in productivity. In order to perform some inferences and other quantitative analysis, the data was weighted into an index of each of the 6 stress elements.

Definitions of the indices are given below:

- Change Index = a measure of perennial economic crisis, uncertainty due to restructure and redundancies and change without consultations

- Demands Index = a measure of administration pressure or demands, workload, working hours, targets and deadlines, family and social demands

- Planning Index = unable to plan for the day due to competing demands

- $\quad$ Relationships Index = work relationships with peers and supervisors

- Work role Index= a measure of unclear job descriptions, roles, career path and promotion prospects

- Support Index = a measure of Lack of support/motivation and participation at work by supervisors and other staff

\section{The channels of result performance were as follows}

Change Index = a measure of perennial economic crisis, uncertainty due to restructure and, redundancies and change without consultations

$\mathrm{X}_{1}=$ perennial economic crisis Likert scale (1 represented "not stressful" and 4 "Very stressful")

$\mathrm{X}_{2}=$ high degree of uncertainty due to restructure and redundancies Likert scale 11 represented "not stressful" and 4 "Very stressful")

$\mathrm{X}_{3}=$ change without consultations Likert scale (1 represented "not stressful" and 4 "Very stressful")

Change Index $=\frac{\sum_{i=1}^{4} X_{i}}{n}$ 
Where, 1 represents "not stressful" and 4 "Very stressful"

Demands Index = a measure of administration pressure or demands, workload, working hours, targets and deadlines, family and social demands

$\mathrm{X}_{1}=$ administration Likert scale (1 represented "not stressful" and 4 "Very stressful")

$\mathrm{X}_{2}=$ increased work load and long working hours Likert scale (1 represented "not stressful" and 4 "Very stressful")

$\mathrm{X}_{3}=$ need to hit targets/deadlines Likert scale (1 represented "not stressful" and 4 "Very stressful")

$\mathrm{X}_{4}=$ family and social demands Likert scale (1 represented "not stressful" and 4 "Very stressful")

Demands Index $=\frac{\sum_{i=1}^{4} x_{i}}{n} \quad$ Where, 1 represents "not stressful" and 4 "Very stressful"

Planning Index $=$ unable to plan for the day due to competing demands. $\mathrm{X}_{1}=$ Dealing with competing demands - unable to plan working day Likert scale (1 represented "not stressful" and 4 "Very stressful")

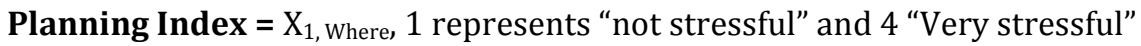

Relationships Index = work relationships with peers and supervisors

$\mathrm{X}_{1}=$ harassment by managers/staff Likert scale (1 represented "not stressful" and 4 "Very stressful")

$\mathrm{X}_{2}=$ new lifestyles of institutional management Likert scale $(1$ represented "not stressful" and 4 "Very stressful")

Relationships Index $=\frac{\sum_{i=1}^{4} X_{i}}{n}$

Where 1 represents "not stressful" and 4 "Very stressful"

Work role Index = a measure of unclear job descriptions, roles, career path and promotion prospects

$\mathrm{X}_{1}=$ unclear job description and job role scale (1 represented "not stressful" and 4 "Very stressful")

$\mathrm{X}_{2}=$ lack of career development opportunities likert scale (1 represented "not stressful" and 4 "Very stressful")

Work role Index $==\frac{\sum_{i=1}^{2} X_{i}}{n}$

Where 1 represents "not stressful" and 4 "Very stressful"

Support Index = a measure of Lack of support/motivation and participation at work by supervisors and other staff

$\mathrm{X}_{1}=$ lack of support and participation at work by supervisors and other staff (1 represented "not stressful" and 4 "Very stressful")

Support Index $=\mathrm{X}_{1}$

Where 1 represents "not stressful" and 4 "Very stressful"

A summary of the descriptive statistics for analysis of the extent to which respondents were stressed with work related factors is presented in table 4 below. 
Table 4: Descriptive Statistics

\begin{tabular}{llllll}
\hline & N & Mean & \multicolumn{2}{l}{ Std. Deviation } & \multicolumn{2}{l}{ Skewness } \\
& Statistic & Statistic & Statistic & Statistic & Std. Error \\
\hline Productivity Index & 188 & .2777 & .42341 & -.716 & .177 \\
Change_Index & 188 & 2.8768 & 1.04874 & -1.168 & .177 \\
Demands_Index & 188 & 2.3891 & .72019 & -.940 & .177 \\
Planning_Index & 188 & 2.02 & 1.013 & .175 & .177 \\
Relationships_Index & 188 & 2.1463 & .94707 & -.166 & .177 \\
Work_role_Index & 188 & 2.4202 & 1.08786 & -.429 & .177 \\
Support_Index & 188 & 2.52 & 1.186 & -.401 & .177 \\
Valid N (listwise) & 188 & & & & \\
\hline
\end{tabular}

Results in table 4 shows that change factors (perennial economic crisis, high degree of uncertainty due to restructuring and redundancies, changes without consultation), Demands or pressure factors (administration, increased work load and long hours, need to hit targets/deadline and family/social demands), Lack of support and participation at work by supervisors and other staff, and Work role (unclear job description and job role, lack of career development opportunities and promotional prospects) are the most stressful factors to a greater extent. On average the general employee in Zimbabwe could be said to be occasionally stressed by the above mentioned factors. Their mean ranges from 2.02 to 2.877. From the skeweness statistic, all the factors are all negatively skewed. The results indicated that indeed all these factors occasionally stress employees in Zimbabwe. This result was consistent with empirical literature, i.e. Michac (1997), Imtiaz \& Ahmad (2009) and Manzoor et al. (2012) who concluded that stress is induced by the following factors: poor time management, unclear job descriptions, feelings of inadequacy and insecurity, inability to get things done, lack of communication, bad personal relationships, quality and complexity of tasks, lack of administrator support, lack of acceptance for work done, low span over work environment, unpredictability in work environment \&inadequate monetary reward, work overload and long work hours, affect on family life, pressure at work, job insecurity. The main objective of the study was to examine the impact of stress related factors on employee productivity. Therefore the weighted data was regressed in order to establish a model for the relationship between the variables. The table below shows the summary of regression output.

\section{Table 5: Regression results}

Coefficients $^{\mathbf{a}}$

\begin{tabular}{|c|c|c|c|c|c|c|c|}
\hline \multirow[t]{2}{*}{ Model } & \multicolumn{2}{|c|}{$\begin{array}{l}\text { Unstandardized } \\
\text { Coefficients }\end{array}$} & \multirow[t]{2}{*}{$\begin{array}{l}\text { Standardized } \\
\text { Coefficients }\end{array}$} & \multirow[t]{2}{*}{$\mathbf{t}$} & \multirow[t]{2}{*}{ Sig. } & \multicolumn{2}{|c|}{$\begin{array}{l}95.0 \% \\
\text { Confidence } \\
\text { Interval for B }\end{array}$} \\
\hline & B & Std. Error Beta & & & & $\begin{array}{l}\text { Lower } \\
\text { Bound }\end{array}$ & $\begin{array}{l}\text { Upper } \\
\text { Bound }\end{array}$ \\
\hline$\overline{\text { (Constant) }}$ & -.021 & .112 & & -.185 & .854 & -.242 & .200 \\
\hline Change_Index & .003 & .041 & .008 & .081 & .936 & -.078 & .085 \\
\hline Demands_Index & .074 & .055 & .126 & 1.358 & .176 & -.034 & .182 \\
\hline Planning_Index & -.029 & .036 & -.068 & -.786 & .433 & -.100 & .043 \\
\hline Relationships_Index & -.059 & .044 & -.132 & -1.331 & .185 & -.147 & .029 \\
\hline Work_role_Index & .128 & .041 & .328 & 3.119 & .002 & .047 & .208 \\
\hline Support_Index & -.005 & .033 & -.014 & -.150 & .881 & -.070 & .060 \\
\hline
\end{tabular}

a. Dependent Variable: Productivity Index

The OLS regression results in Table 5 posits a weak but positive relationship between productivity and conflated work stresses that are related to perennial economic crisis, high degree of uncertainty due to restructure and redundancies, and work changes without consultations. As highlighted stress determinants heighten, productivity is expected to infirmly increase. Generally there is tendency that, if the job market is 
dry, those already employed strive to keep their jobs even if there are uncertainties. Poor work relationships, lack of support at work, and poor planning were found to be stress related factors that negatively affected productivity. Other identified productivity issues were an increase in workplace injuries and accidents, compromised relationships with other workers and failure to meet deadlines.

Stress Management: The study went on further to look at the ways and strategies of managing stress by employees and their responses varied from taking exercises, playing music, praying and reading the bible telling someone. Most of the respondents (22\%) indicated that they talk to someone and share whenever they are stressed. In telling someone, $45 \%$ indicated they tell a close workmate and $31 \%$ said they share with their spouse or family. Though it is good to share, this can have some contagion effects to the family circle of an employee. On the part of the organisations, $29 \%$ of the employees indicated that their organisations are doing nothing as far as stress management is concerned, $17 \%$ indicated that their organisation provide counselling, peer education and stress management seminars. This was a positive to note that companies were also realising that indeed stress exists among employees. Some companies were reported to engage employees into social and other activities like staff wellness campaigns as ways of handling and reducing work related pressure among employees.

\section{Conclusion and Recommendations}

From the research results it was concluded that work related stress manifests itself in many forms amongst employees. Due to the fear of the unknown by employees, due to perennial economic crisis in the country, high degree of uncertainty due to restructurings and redundancies, and work changes without consultations, there was a positive impact of work related stress on employees' productivity. This can be explained by the fact that employees work hard in a bid to defend their jobs. The regression results also show that poor work relationships, lack of support at work, and poor planning were found to be stress related factors that negatively affected productivity. This was consistent with the results of Imtiaz \& Ahmad (2009) who identified lack of administrator support, lack of acceptance for work done as stress factors and their results showed a negative relationship between stress and employee performance.

Recommendation for further research: Future research on this topic should focus on stress effects with respect to a particular industry (i.e. manufacturing, service or government department) and with respect to demographic features.

Policy Implications: It was worrisome to note that some companies are not giving attention to the existence of stress and its effects, and were doing nothing to the well-being of employees. It was therefore recommended that organisations consider the concept of "The Wheel of Life" of an employee is one important concept that can easily be put off balance by the quality of work and work related stress. This was also noted in Abe et al (2016) who noted that "understanding the effectiveness of wellness programmes as work-life balance strategies is necessary especially when the cost of implementing such strategies is considered exorbitant it is recommended that management should take the lead in championing the formulation, implementation (building WLBS portfolio) and promotion of WLBS at the municipality." This will enhance the formulation and implementation of the best strategies for employee's family and work demands and the strategies best suited to workplace stressors.

\section{References}

Abe, E. N., Fields, Z. \& Abe, I. I. (2016). The Efficacy of Wellness Programmes as Work-Life Balance Strategies in the South African Public Service.

Aftab, H. \& Javeed, A. (2012). The impact of job stress on the counterproductive work behavior (CWB): a case study from the financial sector of Pakistan interdisciplinary. Journal of Contemporary Research in Business, 4(7), 590-604.

Aldwin, C. M. (1994). Stress, Coping and Development. An Integrative Perspective, the Guilford Press, New York, NY. 
Bewell, H., Yakubu, I., Owotunse, D. \& Ojih, E. E. (2014). Work-Induced Stress and Its Influence on Organizational Effectiveness and Productivity among Nigerian Workers. African Research Review, 8(1), 112-125.

Blackwell, S. (1998). Organisational Theory. New York: Dorchester Publishing Co., Inc

Bojke, C., Castelli, A., Goudie, R., Street, A. \& Ward, P. (2012). Productivity of the English National Health Service 2003-4 to 2009-10 (No. 076cherp).

Cresswell, J. W. (2003). Research Design. Qualitative, quantitative and mixed methods approach. London: Sage Publications Inc.

Dean, M. (2002). Critical and effective histories: Foucault's methods and historical sociology. Routledge.

Halkos, G. \& Bousinakis, D. (2010). The effect of stress and satisfaction on productivity. International Journal of Productivity and Performance Management, 59(5), 415-431.

http://www.theindependent.co.zw/2015/04/10/distress-and-mental-illness-affects-productivity-in-zim/

Imtiaz, S. \& Ahmad, S. (2009). Impact of stress on employee productivity, performance and turnover; an important managerial issue. International Review of Business Research Papers, 5(4), 468-477.

Industrial Psychology Consultants. (2014). Zimbabwe National Employee Engagement Report.

Leedy, P. D. \& Ormrod, J. E. (2001).Practical research and design.

Lowe, G. (2006). Under pressure: Implications of work-life balance and job stress. Wilson Banwell PROACT Human Solutions, Kingston.

Lowe, G. (2006). Under pressure: Implications of work-life balance and job stress. Wilson Banwell PROACT Human Solutions, Kingston.

Luthans, F. (2002). Organisational Behaviour. New York: McGraw-Hill Companies, Inc

Manzoor, A., Awan, H. \& Mariam, S. (2012). Investigating the impact of work stress on job performance: A Study on Textile Sector of Faisalabad. Asian Journal of Business and Management Sciences, 2(1), 20-28.

Maxon, R. (1999). Stress in the workplace: A costly epidemic. Fairleigh Dickinson University publications.

Meneze, M. N. M. (2006). The impact of stress on productivity of employees at the education training and development practices: Sector education and training authority. Presented at: University of Pretoria., $1-140$.

Michac, J. (1997). Stress and Productivity. Trexima: Slovak Republic.

Miller, J. \& Phipps, G. (2011). Absence management. Absent management survey.1-52.

Naqvi, S. M. H., Khan, M. A., Kant, A. \& Khan, S. N. (2013). Job stress and employees' productivity: case of Azad Kashmir public health sector. Interdisciplinary journal of contemporary research in business, 5(3), 525-542.

NASUWT. (2012). Survey shows that nearly half of teachers have seriously considered leaving the teaching profession in the last 12 months. Accessed at http://www.nasuwt.org.uk/Whatsnew/NASUWTNews/PressReleases/ComResPoll

Organisation for Economic Co-operation and Development. (2001). Measuring Productivity: Measurement of Aggregate and Industry-level Productivity Growth: OECD Manual. Organisation for Economic Cooperation and Development.

Robbins, S. P. (2004). Organisation Behaviour. 11th Ed. New Jersey: Pearson Prentice Hall

Selye, H. (1964). The Stress of Life, Mc Graw-Hill Book Co., New York, NY.

SPRING Singapore. (2011), A Guide to Productivity Measurement.

Treven, S. (2005). Strategies and programs for managing stress in work settings. Management: Journal of Contemporary Management Issues, 10(2), 45-59. 